\title{
"Embarrassingly White"
}

Faculty Racial Disparities in American Recreation, Park, and Tourism Programs

\author{
Rasul A. Mowatt \\ Indiana University
}

Corey W. Johnson

University of Waterloo

Nina S. Roberts

San Francisco State University

\author{
B. Dana Kivel \\ California State University, Sacramento
}

\begin{abstract}
The recruitment and retention of faculty and students of color is a long-standing challenge in academic programs focusing on leisure studies, parks, recreation, and tourism. However, when confronting the predominantly white composition of educational programs, many evade or, at most, acknowledge the situation as a "deficit." Few offer specific strategies for reversing this pattern, if that is the desired outcome. The purpose of this essay is to extend the discourse beyond traditional diversity initiatives by undertaking a field-wide initiative focused on the disparities in faculty and student representation. First, the essay examines systems that have created and supported the persistence of "white" as privileged in academia. Next, a summary and critique of institutional faculty demographic data over the 5-year period from 2006-2011 from four diverse institutions are presented. This analysis illustrates patterns that have resulted in presumably less than desirable numbers of faculty and students of color. Concrete suggestions for recruiting, retaining, and promoting people of color in academic leisure studies programs are included. Increasingly, today's students are attracted to academic programs in which they will be exposed to faculty representing the diversity they will encounter as professionals. This essay offers a call to bridge the perceived gap between practitioners and academia by recommending systemic changes informed by the lived experiences of communities of color that are effectively served by various leisure service providers.
\end{abstract}

Keywords: Communities of color, faculty disparities, race, diversity in higher education

\footnotetext{
Rasul A. Mowatt is an associate professor in the Department of Recreation, Park, and Tourism Studies at Indiana University. Corey W. Johnson is a professor in the Department of Recreation and Leisure Studies at the University of Waterloo. Nina S. Roberts is a professor in the Department of Recreation, Parks, and Tourism at San Frnacisco State University. B. Dana Kivel is a professor in the Department of Recreation, Parks, and Tourism Administration at California State University, Sacramento Please send correspondence to ramowatt@indiana.edu
} 
I know that those who receive this award say they are honored and thrilled. My situation at the University of Oregon complicates my reaction. I was hired as a full professor with tenure in 2001. While I have African ancestry, I identify as multi-racial. At present, there are no full professors who identify as African American or Black in the entire UO College of Arts and Sciences. But I am a woman of color. At present there are only two full professors who are women of color throughout the entire University of Oregon. I am one of them. Given this situation, I am neither thrilled nor honored to receive an award in the name of Martin Luther King at this time, here at the UO. I am embarrassed. I think the absence of African American senior faculty in what presents itself as a world- class research institution is an embarrassment for all members of our community. The black absence is also shameful for those directly responsible insofar as it is caused by selfish cronyism and cults of mediocracy or fear of principled intervention.

-Naomi Zack, Martin Luther King, Jr. Award Recipient at the University of Oregon (Kelderman, 2016)

At the 2011 Society of Park and Recreation Educators conference, more than 50 recreation, parks, and leisure studies faculty and graduate students gathered together to discuss issues related to curricula and teaching. The first night's opening session included a panel of preeminent teachers and scholars, all but one of whom were white, sharing their thoughts and ideas about the future of our profession. The following question was posed by one of the co-authors of this paper to the panel: "What are we concretely doing to ensure that the field is recruiting and retaining both faculty and students of color?" Cautiously, the group began to discuss the merits of the concern, but the conversation was short-lived.

Although this was a conference about pedagogy, it was clear that in this teachable moment, some in the audience were interested in talking about the predominance of "whiteness" in our field, but most were not; and the conversation quickly and inconveniently changed course. It seemed ironic to us that despite being at a conference focused on teaching and learning, that we were met with such resistance to discussing a topic that has been and continues to be an issue in our field-the lack of faculty of color in our field and the lack of diversity among students at our respective universities. As author Tim Wise was quoted, "it is a privilege to ignore the consequences of race in America" (Jha, 2015, p. 109). Currently, the majority of faculty who teach in recreation, parks, tourism, and related fields, are white, and this essay serves as a call to study the why of this reality and possible trend.

We begin this paper by telling this story because it illustrates the challenges associated with discussing uncomfortable topics, such as those related to race, racism, and diversity and the relationship between, in effect, silencing these discussions and maintaining white privilege. Clearly, scholars in our field are interested, theoretically, in these topics. Witness the large number of special issues in various journals devoted to topics such as white privilege, diversity, inclusion, and so forth over the past 16 or so years (a total of six special issues within Journal of Leisure Research, Leisure Sciences, Journal of Park and Recreation Administration). Yet, unfortunately, those special issues that focus on and critique various aspects of our field for its shortcoming with regard to diversity and inclusion, does not seem to manifest in much institutional or structural change for individuals who seek to become members of the academy.

According to research from the Center for American Progress, "by 2043, non-Hispanic whites will become a minority of our population. By 2050, they will be only $47 \%$ of the U.S. population, with communities of color combining to form a solid $53 \%$ majority" (Teixeira, 
Halpin, Barreto, \& Pantoja, 2013). Such demographic shifts will undoubtedly have a longterm impact on social, economic, and political issues and, in turn, will also influence higher education-the complexion of the students, as well as the faculty and future practitioners. This anticipated shift is only a few decades away, but in terms of the current status of students and faculty of color in higher education, the shift seems light-years away. Research suggests that faculty of color only comprise $17 \%$ of all full-time faculty in the United States (Turner, Gonzalez, \& Wood, 2008) and more than $64 \%$ of all undergraduate college students are white (Ross et al., 2012).

We contextualize populations, communities, faculty, and students of color as being inclusive of both racially and ethnically non-white groups despite their numerical significance within certain locales or their ability to showcase academic or professional promise (Vidal-Ortiz, 2008). Vidal-Ortiz (2008) further noted, "it is slowly replacing terms such as racial and ethnic minorities" (p. 1037). But more importantly, the term "allows for a more complex set of identity for the individual-a relational one that is in constant flux" (p. 1038). These non-white or populations of color reflect groups that face historical patterns of discrimination, stereotyping, or marginalization although they may find a measure of success in isolated situations (Alexander, 2004). The disparities in terms of educational attainment and achievement between white students and students of color, and in terms of white faculty and faculty of color, continue to remain a reality and are even further entrenched because of the recent economic downturn of the Economic Recession years (Bartman, 2015; Garibaldi, 2014; Ladson-Billings, 2006; Lee, 2012). As states struggle to fund all public schools, primary, second, and post-secondary, the achievement gap between white students and students of color continues to widen. And when achievement gaps widen, there are fewer students of color in the pipeline to go on to undergraduate institutions and even fewer to go onto graduate degrees. In terms of the field of leisure studies, the numbers for faculty and students of color entering universities to pursue our degrees are low and efforts to recruit and retain students of color have been a long-standing challenge in our field. Yet, despite these low numbers, there have been challenges to even raising concerns about these issues. This muting factor of faculty of color was highlighted in Hibbler and Benedetto (2005),

On one occasion, at a meeting... a senior faculty member shouted in disapproval at how I was conducting the course. He said, "I could lift the phone, make a call, and ruin your career." I remained calm while he engaged in intimidation, threats, aggressive voice and body language. I would not forget his remark, and it makes me curious to know who and where one could call to ruin a person's career. (C. Ramos, in Hibbler, 2002).

The aim of this paper is not a study, but a call to engage in or conduct a study on the racial composition, disparities, and any possible initiatives that have been instituted.

\section{Confronting "Color-Blindness" and Accepting the Need for Racial Awareness}

As colleagues, we (as authors) felt the abandonment of the conversation was a missed opportunity for the collective whole. Furthermore, this shift seemingly forced some faculty concerned with this topic to develop ways to effectively continue the conversation, but 
instead it became a polarizing conversation. A few dominant white, more senior faculty (e.g., full professors) appeared to maintain power and control over the conversation, while a small group who raised various questions felt marginalized and silenced as faculty with more privilege changed the topic with disregard to a significant desire to continue. Again, such a moment could have been instructive, but the more the conversation continued, the more it felt as if the topic was polarizing, with the small group that had raised the issue being marginalized by the dominant group that seemed to maintain power and control over the conversation. This public interaction mirrored what women scholars and educators experienced when they began to raise issues of invisibility and sexism in the field; subsequently, it reinforces an "othering" of individuals and groups.

To further place this discussion in context, a cautionary note was verbalized at this Teaching Institute: “Twenty years ago, representation of people of color was raised as an issue. Ten years ago, it was a serious and persistent problem...Five years from now this may be considered criminal unless we can tangibly devise strategies jointly to reconcile this reality" (Mowatt, Johnson, Roberts, \& Kivel, 2012). A handful of researchers and faculty in our field have, over the past 10 years, started to address the concerns for faculty of color because they continue to remain in the minority. Hibbler (2002) edited a book entitled, Unsilencing the Dialogue: Voices of Minority Faculty and Floyd (2002) contributed to the book by stating:

I remain unconvinced, that we in leisure studies, have the requisite faculties (i.e., skills and training) to undertake serious critique of our treatment of diversity.... Critique is also thwarted by institutional barriers which may be associated with the small presence of scholars of color... there is no one solution (p. 81).

Yet, despite the awareness of the need for change and the awareness of the need for critique, there has been little to no progress on this front despite the fact that in the research literature gains have been made. The gains have come in the form of research that looks beyond differences and what people do for leisure among participants of color to examining institutional issues of racism and white privilege (c.f., Arai \& Kivel, 2009; McDonald, 2009). Indeed, the University of Utah hosted an inaugural conference, Speaking Up and Speaking Out symposium in 2012; focusing on social justice in the academic discipline of RPT, the event was comprised of researchers engaged, or interested in, social justice research to extend the work and discussions beyond specific diversity initiatives of individual institutions. In response to experiences at the 2011 Teaching Institute, the authors of this paper who vary in age, race, ethnicity, religious practices, gender identities and socioeconomic status, decided to develop a presentation to talk about the disparities in the representation of students and faculty of color in the academy. Although diverse in terms of our identities, commonalities are found among our positions on issues of social justice and social change.

The lack of representation of faculty and students of color must be examined at both micro and macro levels; for instance, one's identity influences one's access to higher education and, subsequently, one's professional trajectory within any given academic institution. To begin the analysis in this current essay, we first examined a brief history that has created and kept "white" as privileged and powerful in the academy thereby wielding perpetual dominance among our faculty ranks. Next, we critiqued our respective student recruitment, retention, and graduation data at both the undergraduate and graduate levels over the fiveyear period from 2006-2011 at four institutions (two research intensive and two teaching 
extensive). Finally, we offered concrete suggestions for how faculty of color in recreation and leisure studies programs can be recruited, supported, retained, and promoted. We feel as faculty, who are also professionals in the RPT field, we have unique perspectives that might enhance the growth of our field, and how our students who become practitioners can relate to community interest and social relevance. The voices of faculty from underrepresented populations, as reflected in this paper, are embedded within sentiments of powerlessness that have remained the same as our field has developed. Part of our rationale is based on the often subtle nature of exclusion (e.g., changing a crucial topic of race in faculty representation to something less challenging) presumed to be rooted in racism and white privilege as this is produced and reproduced within the academy (Fenelon, 2002; Hibler, 2003), in journals and on editorial boards, and in our individual disciplines. While these factors of exclusion, powerlessness, or marginalization appear harsh, they are at the forefront of justification for concern yet we acknowledge other variables such as misunderstandings, discomfort, or frustration may come into play with less comprehension of what this might be based on.

Diggles (2014) cautioned that color-blindness perpetuates overt and underlying racial ideologies by

system of privilege and oppression that exists on the basis of race. When this system is ignored or minimized, the disparities that exist between racial [populations] and whites are erroneously attributed to ....shortcomings... as a result, solutions are then aimed solely at fixing those perceived shortcomings (p. 33).

As long as the institutional structure of higher education continues to operate without actively diversifying faculty ranks across race, simultaneously while educating thousands of students about the need for cultural diversity in the communities in which they will work and live, these conversations will, at best, be hollow. At worst, this discourse will continue to mask the underlying issues that go to the heart of the matter in terms of recruitment and retention of faculty of color.

\section{The "Complexion" of Faculty of Color in Higher Education}

From this institution's history, it was clear that faculty diversity was not a priority or administrators were not committed to the idea...the Leisure Studies department was all White, never having had an African-American as part of the faculty, and I was the first and last Latino to hold a faculty position (Hibbler \& Benedetto, 2005).

The problem of the lack of faculty racial diversity is not exclusive to RPT as the issue remains lamentable and problematic in all ranks and fields in higher education as the US populations continues to become more diverse (Gose, 2008). However, the experiences and existence of many faculty of color in RPT remain invisible, underdiscussed, and casually dismissed issues in leisure-based literature and conference proceedings as Hibler's (2002) Unsilencing the Dialogue: Voices of Minority Faculty remains the only published work todate on the subject matter. Other fields have led efforts to begin exploring the prevalence and details of this issue. In education, a critique of the diversity statement at Wright State University prompted the establishment of a standing diversity committee of the College of Education and Human Services (Adams \& Bargerhuff, 2005). The key efforts of the committee were to 1) recruit and retain a diverse student body, 2) recruit and retain a diverse faculty, and 3 ) integrate diversity into the curriculum of the college. The bulk of the 
literature from various fields on the matter of faculty diversity lies outside the professional degree-granting programs (with the exception of education) and within the sciences. Of a more recent note, Kinesiology Review presented a special issue on the matter in 2013. Hodge and Corbett (2013) looked at the experiences of black and Hispanic faculty of color in the United States, and made a similar call for kinesiology to explore the socialization process of Hispanic faculty in the absence of no research studies while calling a more up-to-date study on the experiences of black faculty (Hodge \& Stroot, 1997).

Researchers within science and engineering studied the low percentages of women and students of color due to the historic nature of those percentages at the top research programs in the U.S. (Beutel \& Nelson, 2005). Beutel and Nelson (2005) reported that the populations of color, specifically black and Latino/a, comprised only $4.1 \%$ of all university faculty in science and engineering. While in schools of medicine, faculty of color (black and Puerto Rican descent) are often at a disadvantage in matters of promotion than their white counterparts as rates for promotion were found to be larger for underrepresented minority faculty despite the rate of representation increased (Fang, Moy, Colburn, \& Hurley, 2000). However, a follow-up study indicated that faculty diversity numbers in 82 of 107 institutions have waned since the early 2000s with representation topping out at $3 \%$ for black faculty and $4.2 \%$ for Latino/a faculty (Page, Castillo-Page, \& Wright, 2011). Interestingly, Peterson et al. (2004) found that faculty of Color reported low rates of career satisfaction despite being just as productive as their White counterparts from a sample of 1,979 faculty from 24 medical schools.

\section{Locating Whiteness and an Absence of Color in Strategies}

I believe our education system as a whole has not integrated the histories of all people into our education system, just the Eurocentric view of itself, and the White-centered view of African Americans, and even this is slim to nonexistent. What I find is that most people don't know the fact they don't know, because of the complete lack of information.

\section{-Ronald Takaki}

A Different Mirror: A History of Multicultural America

Alemán (2014) cautioned that solely focusing on increasing the representation of faculty of color is not enough. A close examination of socialization processes is also merited and necessary. The value orientation on selection and discussion of topics within courses, approach to working with communities, and validation of perspectives are often from a white lens as Alemán remarked within her own field of journalism. Counseling psychology has found some measure of success in recruiting faculty of color. (Moradi \& Neimeyer, 2005). Moradi and Neimeyer (2005) are careful in identifying that this increase is not endemic of a new institutional outlook on diversity but of years of consistent challenging of institutional norms as they point out that a greater awareness of the "lived" experience of faculty of color need to shared (for example, are they accomplishing what they have set as goals or markers of achievement?). As Shen-Miller, Forrest, and Burt (2012) found, faculty of color are fearful of the consequences when they may assert their cultural identity or raise questions from their unique perspectives; this occurs especially in relationship to the preparation of new practitioners working with diverse populations. Yet, within sociology the realities of long persistent racial attitudes, such as their hire or promotion is a product 
of Affirmative Action or racial sympathy, are experienced by faculty of color, broadly, and women faculty of color, specifically (Smith \& Calasanti, 2005). This is exacerbated by the classroom experiences of women faculty of color in dealing with racial hostilities from students that are condoned or marginally addressed by department chairs (Pittman, 2010).

The findings from other academic disciplines exists alongside broader university-level diversity efforts in faculty recruitment, retention, and promotion that have been the least successful throughout the U.S. (Allen et al., 2002; Smith, Turner, Osei-Kofi, \& Richards, 2004). Faculty of color, all self-identified non-white faculty, constituted $17 \%$ of all faculty at four-year institutions (Asian, black, Latina/o, and Native American) (Fenelon, 2003; Peterson et al., 2004). This number dwindles to below $12 \%$ when separately accounting for full professor rank and to a dismal $1 \%$ for female faculty of color. Across "the big pond," a recent study reported only 50 black faculty members among the 14,000 faculty throughout Great Britain (Shepard, 2011).

In addition to various U.S. institutions of higher education engaging in diversity efforts (albeit occasionally unsuccessful), the complex experiences of faculty of color in the academy has been widely researched outside of RPT programs. The experiences of faculty, especially as they enter the academy out of graduate school can be challenging, but the challenges for faculty of color are even more difficult because of sample manifestations of historical racism (slavery, segregation, access to education, etc.). According to Cora-Bramble (2006), there are slower rates of scholarly and professional advancement for faculty of color. Other studies have identified feelings of isolation (Price et al., 2005), lack of formal and informal networks and racial discrimination (Nunez-Smith et al., 2007), enormous committee work falling on diverse faculty (Knowles \& Harleston, 1997), and racially motivated classroom incivility (Cao, 2011). So, while most white faculty may take for granted that their integration into the academy will be challenging because of having to navigate bureaucracy, faculty of color will have an additional set of issues to negotiate having to do with how their racial identities are perceived by others and their white colleagues unconscious bias.

Turner, González, and Wood (2008), for instance, documented and analyzed 252 publications from 1988-2007 on the subject of the status and experiences of faculty of color in academia, none of which were in any leisure studies-related journals. Their research took the necessary steps in using a range of search engines and tools; a total of 21 different avenues were used to find sources. Further, they isolated keywords in their search incorporating various identities for faculty of color; for example, Asian and Asian American; Native American, Indigenous, Indian, and American Indian; and also underrepresented and minority.

Their results also accounted for evidence in the research purpose, theoretical framework, questions, methodology, findings, recommendations, future implications, and conclusions. In their synthesis of journal articles, books, book chapters, conference proceedings, dissertations, theses, and institutional reports they identified three contexts and several themes. In their study, all themes fell under, or cross-pollinated into, the three contexts of departmental, institutional, and national contexts of diversification. Some departmental context specific themes that emerged from the literature and publication synthesis were: the love of teaching, undervaluation of research interests, challenges to intellect in the classroom, tokenism, and isolation. The departmental context represented all activities or structures that impacted a faculty of color's experience such as courses, committees, mentorship, promotion and tenure requirements, and structures for annual reporting. 
From Turner et al. (2008), the themes that emerged from the institutional context included role of networks, allies, and colleagues; lack of faculty and student diversity; support programs for faculty of color; and the presence of racism, classism, and sexism in the workplace. Within the institutional context evidence of the experiences of faculty of color were represented by promotion and tenure standards across campus, campus-level committees, and the university's reputation, among others. In contrast, the national context yielded the following themes: failure to implement Affirmative Action policies; illegitimacy of research; and economic subordination via persistent salary inequities. Last, the national context focused on evidence that linked to national associations/organizations, national political climate and legal trends (e.g., challenges to Affirmative Action), off-campus climate at faculty's home institution, and journal editorial boards. How, then, does all this relate to white privilege in the Academy and how is it being addressed?

\section{White Privilege in the Academy}

At the heart of discussions about diversifying faculty of color is the recognition that the absence of diversity in the academy is due to a variety of complex and interrelated issues. Explanations for underrepresentation include disproportionately large numbers of white students enrolled in colleges, students who have the resources, community and family support to pursue higher education compared with students of color who are often tracked into low-performing high schools, a lack of opportunities for Advanced Placement classes and exams, and poor resources to encourage students of color to pursue postsecondary education. And when students of color do make it to college, their drop-out rates and time to graduation rates are often higher than white students, thus putting them behind their peers in terms of scholarship and grant opportunities to pay for school (Bartman, 2015; Garibaldi, 2014; Ladson-Billings, 2006; Lee, 2012).

Regarding journal editorial boards, Stanley (2007) noted there is incessant "disciplinary" gatekeeping when counter narratives (the perspectives of faculty of color) come up against master narratives (Western, white philosophical tradition) in the editorial review process. In finding a home for this paper, the authors have been met with three outright rejections from editors without review as the paper did not meet the scope of a leisure-related journal. Although we cannot say this unequivocally corroborates Stanley, it does speak to a type or level of gate-keeping that does exist. However, Stanley is clear in articulating the ways in which the master narrative is present in journals: (1) use of terms, (2) methodologies, (3) presence of "color-blindness," and (4) the questioning of one's intellect in review feedback. For example, the preponderance of the term "at-risk" to define youth programs targeting youth of color is often assumed without justification. At-risk, according to Stanley (2007), refers to the experiences and work with these youth from a deficit model as they are looked upon as lacking certain skills, intelligences, and abilities.

A counter-narrative noted discussions that included young people as being enriched with backgrounds and perspectives needing to be tapped. The use of the term "minority" could be linked with her assessment of linguistics, as it has less quantifiable representation, rather a position of perpetual inferiority. One can ask, "When is the minority ever the majority in the U.S.?" Throughout this manuscript the term "faculty of color" is used instead of "minority" as it might be more empowering and inclusive of both racial and ethnic classifications. Stanley's (2007) research is remarkable as it actually uses the feedback from reviewers responsible for manuscripts submitted by faculty of color to highlight 
the disparate comments on the same review. Comments praised, but also recommended changes in epistemology that would radically alter the submitted work. Comments that rejected the work called into question the very reason why the author was in academia as well as "wasting" one's time in reviewing something of little merit. Stanley also indicated that one comment went as far as to question the method the researcher used to recruit research participants, "are these subjects, in fact, friends of the author?" (2007, p. 19). Such negative feedback to young scholars of color may have a chilling effect and is a form of intellectual violence (abuse and victimization), thus further silencing their potential contributions in their respective fields. It should also be noted that feedback occurred on submitted manuscripts of 15 faculty sent to a special issue on the teaching experiences of black faculty at predominantly white research universities. Nonetheless, what was revealed to be even more harmful is the responses from potential faculty of color who declined to participate in the study as many felt that "their narratives were too painful to share, while others expressed they could be targeted because they were among a few, or the only ones, in their departments [or fields]" as they sought tenure-track positions or tenure (p. 19).

A "Call for a Special Issue" early in 2013 further served to illustrate the problem with gatekeeping. That recent call for papers on the scholarship of teaching and learning listed the names of the authors who will provide anchor papers for this particular issue, the coeditors, and the main editors for this journal. This was a typical call for a "special issue" that was also typical in another way; that is, all seven of the people directly or indirectly connected to this special issue were white, middle-aged men. When questioned about the composition of the gatekeepers for this issue, the editors were immediately apologetic and acknowledged that they had not even "noticed" that anything was amiss in this very call for submissions. This anecdote is a perfect illustration regarding the insidiousness of race and gender-based privilege and how it operates to obscure privilege based on gender and race of the gatekeepers. Seeking to instill a sense of purpose to our field (or any discipline), even White colleagues with the best intentions are, at times, remiss in such decisions because they may lack the depth of cultural competency alongside those intentions or unconscious biases that are required to see their actions through a more inclusive lens.

\section{Critique of Diversity and Barriers Regarding Recreation, Parks, and Leisure Studies}

Below we offer snapshots of the faculty of color from academic institutions where the authors serve, two teaching and two research. We do so as a way to illustrate the needs of our respective student recruitment, retention, and graduation data at the undergraduate and graduate level over a selected five-year period from 2006-2011. While in the backdrop, data derived from the National Center of Education Statistics (see Table 1; Snyder \& Dillow, 2012) show the most recent summary of degrees conferred by race, ethnicity, and gender in leisure studies. In the subsequent section we then offer sample strategies for effectively recruiting, retaining, and supporting faculty.

\section{Midwestern Research University}

In 2012, the most current numbers report 279 tenured and tenure track faculty of which 59 are faculty of color within the School of Public Health-Bloomington out of a total of 1, 372 total faculty on campus. Within the 59 faculty of Color: 33 International 
Asian, 15 Black, 5 multiracial, 4 Latina/o, and 2 Alaskan/Native American. Specifically within the department of Recreation, Park, and Tourism Studies, there are 34 full-time faculty, 3 International Asian, 1 Hispanic, 1 Native American, and 1 Black. These disparities correlate to graduate students of Color representation within the department: 53 White, 22International (Asian), 6 Black, and 1 Latina/o.

\section{Southern Research University}

As of 2012, there are 227 total university faculty, of which 50 are faculty of color, this is out of a total of 1,609. Within the 50 faculty of color: 15 Asian, 26 Black, 5 Latina/ 0 , and 1 Alaskan/Native American, 1 Lebanese, 1 Russian, 1 unknown, and 0 multiracial. Specifically within the department of 28 full-time faculty, 10 are racially diverse (2 Asian, 6 Black, and 2 Latina/o). These disparities correlate to graduate students of color representation within the department: 142 White, 2 International (Asian), 75 Black, 8 Latina/o, 2 Island Pacific, and 1 mixed race. In the Recreation and Leisure Studies program level, at the time had 18 graduate students with 2 of those being Black and the remaining White.

\section{West Coast Teaching University \#1}

There are 394 total university faculty including 152 faculty of color (39\%) in the College of Health and Social Sciences. These 2012 totals included 271 females and 123 males. The racial diversity, specifically, includes 30 Latino, 17 Black, 54 Asian/Asian American, 17 Pacific Islander (i.e., Filipino and Samoan), and 3 Native/American Indian (note: 31 are unknown based on faculty who declined to provide race data to the college). Within the Department of Recreation, Parks, and Tourism, there were 6 full-time faculty (i.e., 50/50 females/males) and the racial composition consisted of 3 white males, with females identifying as White, Black, and Biracial.

\section{West Coast Teaching University \#2}

In 2012, there were 245 faculty including 54 faculty of color. These totals also included 152 females and 93 males. The racial diversity included 18 African Americans, 4 American Indians, 16 Asian Pacific Islanders (i.e., Filipino and Samoan), 16 Latinos. Three faculty identified as multiracial; and 18 declined to state their racial/ethnic identities. There were a total of 170 White/Caucasian faculty. In terms of Caucasian faculty, there were 1,045 (70.7\%). Specifically, within the department, there were eight full-time tenure-track faculty: four women, four men, and the racial composition consists of seven white males and females and one person who is African American.

\section{Professional Implications of a Lack of Faculty Diversity}

As Anderson and Stone (2005) noted, professionals must increase their cultural competency that goes beyond a generalized awareness of difference. Leisure service professionals (practitioners and faculty) must have the necessary set of cultural skills to work with and engage diverse communities, race being just one identifiable marker of communities of difference. Engagement with a diverse faculty may present opportunities to think differently about programmatic decisions, resource allocation, and even promotions. The lack of a potentially "other" perspective presents a disservice on one hand to students and on the other hand, it also presents a model of representation and authority that can be replicated, unintentionally, in professional settings. 


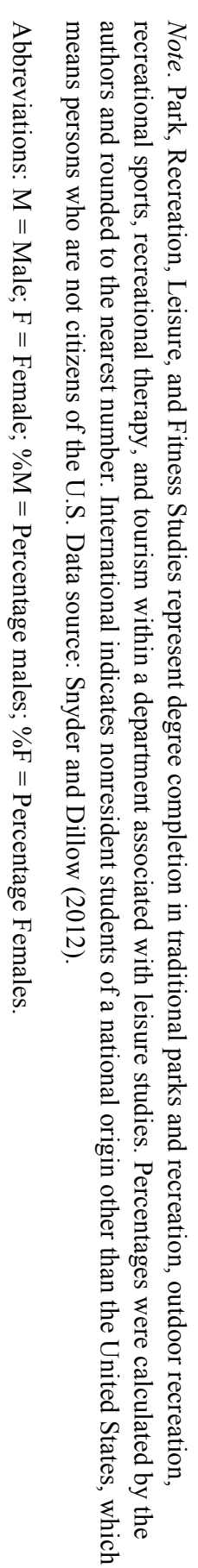

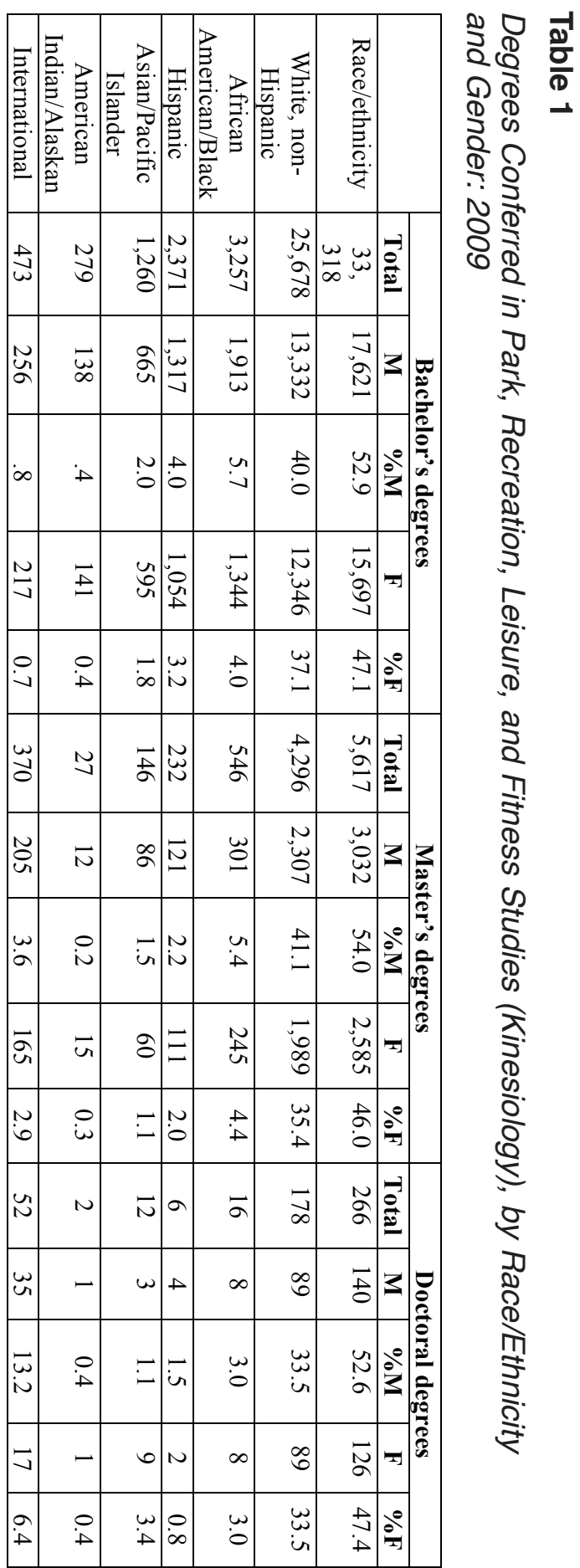


In interviewing 37 senior-level managers within the Young Men's Christian Association (YMCA), Outley and Dean (2007) were able to conclude that homosocial reproduction influenced the underrepresentation of African Americans in senior-level positions within the organization. The mundane nature of interacting with those who are like you, and whom you like has resulted in a lack of representation for an organization that has a long history of involvement in racially diverse communities. Outley and Dean (2007) posited that "[YMCA] organizational leaders tend to hire and promote people like themselves because it is an expedient way to ensure that those selected are compatible with existing norms and expectations" (p. 88). A lack of socialization opportunities, in turn, negatively resulted in a lack of promotional discussions and opportunities as homogeneity. Outley and Dean further commented "that members of a dominant group tend to recruit, nurture, and promote persons like themselves, especially when they are selecting individuals for prestigious, confidential, and trusted positions" (p.78). Additionally, when diversity occurred in job placement and authority within the organization, it was often tied to racialized jobs (diversity officer or within a predominantly black community) that is very similar to Allison and Hibbler's (2004) look at parks and recreational professionals. The interaction for a student with a racially diverse faculty breaks up the commonality of homosocial environments and relationships based on classroom instruction, advising interactions, and possibility of mentoring situations.

The recommendations set forth by Bedini, Stone, and Phoenix (2000) on increasing the diversity of students can be greatly actualized by an equal push to diversify the faculty. Alongside other effective efforts that resulted in a $23 \%$ increase of African American students at the University of North Carolina at Greensboro, the authors worked within a case study/program that offered a tutoring, mentoring, and advisory task force with African American representation that greatly excited and engaged those students to think about the RPT major and complete their degree program. The increased presence in the classroom (specifically students, but can be extended to faculty) can reduce the feelings of tokenism and the need to represent a "race" that was reinforced with the focus group responses on racial/cultural disconnection felt by racially diverse students in another academic program where the lack of faculty diversity was strikingly similar to the student diversity (Waller, Costen, \& Wozencraft, 2011). In the Waller et al. (2011) study, some respondents even remarked that "when I was looking for programs and I looked at people's websites, if there were no men or women of color in their program, I automatically 'X-ed' them off my list for schools that I would consider for a PhD program" that illustrates a concern for future upper administration efforts (Waller et al., 2011, p. 41). Although Bedini et al. (2000) make mention of inviting guest speakers of diverse backgrounds can assist, the importance of racially diverse faculty within the institution could have the greatest effect. The increase was a result of a strategically targeted grant over a five-year period to diversify the student body and, as a result, the profession of therapeutic recreation/recreation therapy

\section{Strategic Changes in Recruitment, Retention, and Promotion}

Strategic changes in recruitment, retention, and promotion need to occur simultaneously at all three levels: departmental, institutional, and national. In this section, we examine what the research literature says about effective strategies and also offer suggestions based on professional observations that, collectively speaking, span more than 30 years in the academy. What was gleaned from Turner, González, and Wood (2008), in their synthesis of 
252 sources of research on faculty of color experiences, are several sound recommendations that RPT programs should consider individually or preferably collectively, based on the following three contexts: departmental, institutional, and national.

\section{Departmental Level}

Departments should diversify their processes for faculty evaluation (pre- and posttenure) to account for alternative ways of knowing, instructional styles, and academic voice in writing. In terms of meaningful change, the department level has the most direct and immediate impact on a faculty member's experience (Campbell \& O'Meara, 2014). These strategies include reducing isolation, ensuring that faculty of color are involved in departmental committees but not unduly burdened by these commitments, and ensuring that retention and promotion assessments include a variety of evaluative strategies that encompass multiple ways of knowing and of conducting research. Knowles and Harleston (1997) noted that both faculty of color and women often bear a greater burden in terms of service requirements. Department chairs can play an important role in terms of mentoring junior faculty to pursue service requirements that will help to advance their careers but not be overly or unduly burdensome. In response, some institutions have identified this responsibility as a formal part of chair duties. Similarly, retention and promotion documents should be assessed to clarify the value of service in terms of retention and promotion.

\section{Institutional Level}

One of the issues identified by Price, et al. (2005), the feeling of isolation, should be addressed formally and informally. To what extent do faculty of color feel included and an integral part of the department and its culture? Interactions as benign as asking someone out for coffee or including them in social interactions with other peers and colleagues should not be overlooked or assumed to be insignificant. Interestingly, our research confirms that it is often in social settings and situations that people develop networks and connections that assist them both personally and professionally.

Another institutional recommendation is to provide training to all relevant staff on a myriad of issues faced by faculty of color from college deans and department chairs, to administrative assistants (e.g., helping with promotion/tenure documents). The national recommendations put forth by Turner et al. (2008) were clear in stating the need for institutions, associations, and organizations to maintain relationships with communities of color alongside addressing the persistent salary inequities that perpetuate faculty of color at all ranks. Smith (2011) referred to this manner of training as a necessary in building symmetry.

Based on the distance from positions of authority and decision making, faculty of color are left with little ability to influence their respective institutions for the better, while those in position of privilege have little impetus to see or affect change that they may benefit from minimally. Using Adams and Bargerhuff's (2005) study on the effects of an empowered diversity committee, it is vital that the dialogue of those issues of faculty of color are presented in formal settings with clear tasks, appropriate budgets, and institutional support.

\section{National Level}

At the national level, faculty need to support their administrators, in the department and at the college and institutional levels, to advocate for more faculty of color hires, to advocate for funding to support lines for faculty of color, and to close the economic gap 
based on race. While at the national level, collectively, RPT programs could work with Historically Black Colleges and Universities and the Educational Testing Service (Knowles \& Harleston, 1997) to identify potential graduate students of color for the various master's and doctoral degree-granting institutions. Hence, the advantages of a racially diverse faculty could offer RPT disciplines a gateway into broader perspectives has been influenced by the fields and disciplines of psychology, sociology, and anthropology and the use of methods and concepts have been long accepted. There may need to be a greater acceptance and understanding of the nuanced ways that African Studies, American Studies, Asian American Studies, Asian Studies, Black Studies, Caribbean and Latin American Studies, Cultural Studies, Latino/a Studies, Middle Eastern Studies, and Native American Studies could offer RPT new approaches to looking at the experiences of diverse populations. Certainly, the expansion of many traditional parks and recreation programs into tourism and hospitality has broadened opportunities to examine people of color in the global leisure context. Each area's research has methodological considerations and cultural appropriateness that may widen our research to new audiences but also attract promising scholars from those area studies that may wish to study leisure-based subject matter.

Cultural appropriateness is how we adjust the literature, information, and research for targeted populations that a field wishes to improve and advance service or present information for (Kreuter et al., 2002). If we recognize that our readers are multi-racial and that they could become faculty, then cultural appropriateness presents several approaches or strategies on accomplishing this: 1) peripheral strategies (packaging materials that overtly convey relevance to a group); 2) evidential strategies (relay information, outcomes, and evidence that directly impacts a group); 3) linguistic strategies (make materials more accessible in the dominant or native language of the group); and 4) constituentinvolving strategies (involving and hiring from the group), and sociocultural strategies (the integration of the group's values, beliefs, and behaviors in the dominant discourse). Each of these alternative ways counter the intentional or unintentional gatekeeping that promotes "legitimate" and traditional processes of evaluation that only serve to either deter faculty of color from growing within their line of research or inhibit their ability to advance.

The most important of Turner et al's (2008) recommendations, is based on their synthesis of research methods applied within the aforementioned 252 publications. For RPT to embark on a national (U.S.) or regional (North American) self-study based on their findings, we recommend that a combination or all of the following be used: (1) interviews, (2) surveys and questionnaires, (3) large data sets (institution numbers on hiring), (4) document analysis, and/or (5) observations. The focus of the study should be four-fold: 1) Over a 10-year period, chart the numbers of undergraduates, graduate, and faculty of color from a representative sample of programs in North America; 2) Over the same period, chart the specific progression of doctoral students within the field to faculty positions and then the promotion of those faculty; 3) From a representative sample (based on gender, sexual orientation, disability, and age), interview a group of faculty about their experiences; and lastly, 4) Provide an evidence-based table of existing (and official) programmatic efforts in recruiting and retaining racially diverse master's and doctoral students as well as faculty that have existed at the same representative sample of programs over the same 10-year period, noting those efforts that no longer exist. This may be enhanced by use of software that tracks such efforts and reduces unintentional personal bias.

Further, such study could also effectively isolate the results of certain experiences to specific faculty of color based on gender and language (including accent), along with 
intra-racial identity (e.g., black can be African American, African, Afro Caribbean, Afro Canadian, Afro-Cuban, etc.) (Sims, 2006). Turner et al. (2008) also cautioned that oftentimes the experiences of faculty of color with multiple identities failed to be captured within the research such as experiences based on sexual identity, language differences, or even domestic versus international forms of diversity. Brief scenarios presented earlier in this examination could serve as the base for an expanded set of case studies that could be used at various organizational levels to identify areas of ranging from blatant disregard unintentional bias, and open the doors to a dialogue on concerns many felt were closed.

\section{Concluding Remarks}

When looking at the issue of faculty disparities, a holistic and comprehensive approach is necessary to address the challenges (Hutchinson, 2012). Beyond traditional areas of academic duty (research, teaching, and service), issues remain in myriad successful research funding opportunities, specifically major granting agencies like the National Institute for Health (Ginther et al., 2011). Thus, all this implores-for those least affected by these disparities-to initiate research to identify issues, specifically within RPT, and then collaborate to aggressively address the disparity.

The benefits of taking this path should be obvious as research about student learning has illustrated how ethnically diverse faculty generally enhance the educational experience of college students (Umbach, 2006). Similarly, such cultural pluralism impacts the relevance to the profession for developing relationships with the diverse communities we seek to serve (Bedini, Stone, \& Phoenix, 2000; Msengi et al., 2007). The aim of resolving the disparities among faculty is less about finding the "right" answer, but simply moving the discourse into appropriate actions to find an answer at all. If RPT and related departments are serious about advocating for social justice around the predominantly white composition, we need to launch intentional and strategic initiatives to change our "color" and augment a sense of cultural competency vital to success. Given a growth of ethnic diversity among the students served in our field, it's embarrassing in many ways to continue seeing a lack of similar diversity among the faculty.

All levels of the university system should engage in outreach efforts that dispel the common myth that "anyone can teach" and market teachers as treasured, knowledgeable professionals in our field as much as any other discipline. Gathering and directing the resources needed to produce the well-prepared, ethnically diverse, and culturally sensitive faculty workforce that our classrooms demand, is likely to rest on recognizing the fact teaching is the profession that "shapes America's future." As the U.S. becomes more racially diverse (e.g., people of color will be the majority by 2050), colleges and universities are expected to diversify faculty hires at greater strides. We need to inspire more graduate students of color to pursue faculty positions, construct targeted hiring opportunities, establish minority-specific post-doc opportunities, and augment our scholarship regarding race, culture, and equity.

Finally, culturally appropriate recruitment strategies and multicultural, research/ teaching fellowship programs can (theoretically) produce favorable outcomes for potential faculty of color. These sorts of recruitment tactics can also likely help diminish some of the socio-cultural challenges some faculty of color may encounter in higher educational settings. There is no easy pathway to success and challenges abound; change is not possible any other way. The academy and the profession alike (e.g., via NRPA) needs to address 
these disparities at both micro and macro levels. Providing more outreach, inspiring more students of color to pursue higher education degrees, and refining recruitment strategies is not enough. We must also be proactive in recruiting allies across our respective campuses and within our profession to identify and challenge racism and the manifestations of racism and racial disparities.

\section{References}

Adams, K., \& Bargerhuff, M. E. (2005). Dialogue and action: Addressing recruitment of diverse faculty in one Midwestern university's college of education and human services. Education, 125, 539-545.

Alemán, S. M. (2014). Locating whiteness in journalism pedagogy. Critical Studies in Media Communication, 31(1), 72-88. doi: 10.1080/15295036.2013.808355

Alexander, B. K. (2004). Racializing identity: Performance, pedagogy, and regret. Cultural Studies, Critical Methodologies, 4(1), 12-27. doi: 10.1177/1532708603251810

Allen, W., Epps, E. G., Guillory, E. A., Suh, S. A., \& Bonous-Hammarth, M. (2002). The black academic: Faculty status among African Americans in U.S. higher education. The Journal of Negro Education, 69(1/2), 112-127.

Allison, M. T., \& Hiibler, D. K. (2004). Organizational barriers to inclusion: Perspectives from the recreation professional. Leisure Sciences, 26, 261-280. doi: 10.1080/01490400490461396

Anderson, D. M. \& Stone, C. F. (2005). Cultural competencies of park and recreational professionals: A case study of North Carolina. Journal of Park \& Recreation Administration, 23(1), 53-74.

Arai, S., \& Kivel, B. D. (2009). Critical Race Theory and social justice perspectives on whiteness, difference(s) and (anti)racism: A fourth wave of race research in leisure studies. Journal of Leisure Research, 41(4), 459-472.

Bartman, C. C. (2015). African American women in higher education: Issues and support strategies. College Student Affairs Leadership, 2(2), Article 5. Retrieved from http:// scholarworks.gvsu.edu/csal/vol2/iss $2 / 5$

Bedini, L. A., Stone, C. F., \& Phoenix, T. L. (2000). Increasing diversity among students in recreation, parks, and leisure studies curricula: A case study. Schole: A Journal of Leisure Studies and Recreation Education, 15, 47-62.

Beutel, A. M., \& Nelson, D. J. (2005). The gender and race-ethnicity of faculty in top science and engineering research departments. The Journal of Women and Minorities in Science and Engineering, 11(4), 50. doi: 10.1615/JWomenMinorScienEng.v11.i4.50

Campbell, C. M., \& O’Meara, K. A. (2014). Faculty agency: Departmental contexts that matter in faculty careers. Research in Higher Education, 55(1), 49-74. doi: 10.1007/ s11162-013-9303-x

Cao, W. (2011). An inconvenient identity: Paradox, complexity and strategies in a social foundations classroom. Education and Urban Society, 43(4), 517-532. odi: $10.1177 / 0013124510380719$

Cora-Bramble, D. (2006). Minority faculty recruitment, retention and advancement: Applications of a resilence-based theoretical framework. Journal of Health Care for the Poor and Underserved, 17, 251-255. doi: 10.1353/hpu.2006.0057

Diggles, K. (2014). Addressing racial awareness and color-blindness in higher education. New Direction for Teaching and Learning, 2014(14), 31-44. doi: 10.1002/tl.20111 
Garibaldi, A. M. (2014). The expanding gender and racial gap in American higher education. The Journal of Negro Education, 83(3), 371-384. doi: 10.7709/ jnegroeducation.83.3.0371

Ginther, D. K., Schaffer, W. T., Schnell, J., Masimore, B., Liu, F., Haak, L. L. \& Kington, R. (2011). Race, ethnicity, and NIH research awards. Science, 333(6045), 1015-1019. doi: $10.1126 /$ science. 1196783

Gose, B. (2008, September 26). Whatever happened to all those plans to hire more minority professors? Chronicle of Higher Education. Retrieved from http://chronicle.com/ weekly/v55/i05/05b00101.htm.

Fang, D., Moy, E., Colburn, L., \& Hurley, J. (2000). Racial and ethnic disparities in faculty in academic medicine. The Journal of the American Medical Association, 284(9), 10851092. doi: 10.1001/jama.284.9.1085

Fenelon, J. (2003). Race, research, and tenure: Institutional credibility and incorporation of African, Latino, and American Indian faculty. Journal of Black Studies, 34(1), 87-100. doi: $10.1177 / 0021934703253661$

Floyd, M. F. (2002). Deconstructing diversity in leisure studies. In D. K. Hibbler (Ed.), Unsilencing the dialogue: Voices of minority faculty (pp. 75-83). Miami, FL: Florida International University Center for Urban Education and Innovation.

Hibbler, D. K. (Ed.). (2002). Unsilencing the dialogue: Voices of minority faculty. Miami, FL: Florida International University Center for Urban Education and Innovation.

Hibbler, D. K., \& Benedetto, C. L. (2005). The feeling of difference: Minority faculty experience in academe. School for New Learning Faculty Publications. Paper 43. Retrieved from http://via.library.depaul.edu/snl-faculty-pubs/43

Hodge, S. R., \& Corbett, D. R. (2013). Diversity in Kinesiology: Theoretical and contemporary considerations. Kinesiology Review, 2(3), 156-169.

Hodge, S. R., \& Stroot, S. A. (1997). Barriers and support structures perceived by African American and Caucasian physical educators during their career development. Equity \& Excellence in Education, 30, 52-60. doi:10.1080/1066568970300308

Hutchinson, J. F. (2012). Parallel paradigms: Racial diversity and racism at universities. In A. Smedley \& J. F. Hutchinson (Eds.), Racism in the academy: The new millennium (pp. 34-48). American Anthropological Association. Retrieved from http://www.aaanet. org/cmtes/commissions/Racism-in-the-Academy-New-Millennium.cfm

Jha, S. R. (2015). Pre-post racial America: Spiritual stories from the front lines. St. Louis, MO: Chalice Press.

Kelderman, E. (2016, January, 20). Dearth of faculty diversity leaves King award recipient 'Neither thrilled for honored'. The Chronicle of Higher Education. Retrieved from http:// chronicle.com/article/Dearth-of-Faculty-Diversity/234974

Knowles, M. F., \& Harleston, B. W. (1997). Achieving diversity in the professoriate: Challenges and opportunities. Ann Arbor, MI: American Council on Education.

Kreuter, M. W., Lukewago, S. N., Bucholtz, D. C., Clark, E. M., \& Sanders-Thompson, V. (2002). Achieving cultural appropriateness in health promotion programs: Targeted and tailored approaches. Health Education and Behavior, 30(2), 133-146. doi: $10.1177 / 1090198102251021$

Ladson-Billings, G. (2006). Presidential address: From the achievement gap to the education debt: Understanding achievement in U.S. schools. Educational Researchers, 35(7), 3-12. doi: 10.3102/0013189X035007003 
Lee, J. (2012). Does universalism hold in academia?: Focusing on women and racial minority faculty. Journal of the Professoriate, 6(1), 48-66.

McDonald, M. G. (2009). Dialogues on Whiteness, leisure, and (anti)racism. Journal of Leisure Research, 41(1), 5-21.

Moradi, B. \& Neimeyer, G. J. (2005). Diversity in the ivory white tower: A longitudinal look at faculty race/ethnicity in counseling psychology academic training programs. The Counseling Psychologist, 33(5), 655-675. doi: 10.1177/0011000005277823

Msengi, I., Farland, J., Pedescleaux, J., McGloster, M., \& Yang, H. (2007). Program effectiveness and curriculum competencies of the Leisure Youth and Human Service Division at a Midwestern University: Does the curriculum meet the needs of the leisure profession? SCHOLE: Journal of Leisure Studies Recreation Education, 22, 29-44.

Mowatt, R. A., Johnson, C. W., Roberts, N. S., \& Kivel, D. (2012, May). Embarrassingly White: Changing the "color" of higher education in parks, recreation, and leisure studies. Presentation at the Social Justice in Leisure Studies Conference. Salt Lake City: The University of Utah.

Nunez-Smith, M., Curry, L. A., Bigby, J. A., Berg, D., Krumholz, H. M., \& Bradley, E. H. (2007). Impact of race on the professional lives of physicians of African descent. Annals of Internal Medicine, 146(1), 45-52. doi: 10.7326/0003-4819-146-1-200701020-00008

Outley, C. W., \& Dean, W. (2007). Factors affecting the upward mobility of African Americans in the Young Mens Christian Association Movement. Journal of Park and Recreation Administration, 25(1).

Page, K. R., Castillo-Page, L., \& Wright, S. M. (2011). Faculty diversity programs in U.S. medical schools and characteristics associated with higher faculty diversity. Academic Medicine: Journal of the Association of Medical Colleges, 86(10), 1221-1228. doi: 10.1097/ACM.0b013e31822c066d

Peterson, N. B., Freidman, R. H., Ash, A.S., Franco, S., \& Carr, P. L. (2004). Faculty selfreported experience with racial and ethnic discrimination in academic medicine. Journal of General Internal Medicine, 19(3), 259-265. doi: 10.1111/j.1525-1497.2004.20409.x

Pittman, C. T. (2010) Race and gender oppression in the classroom: The experiences of women faculty of color with white make students. Teaching Sociology, 38(3), 181-196. doi: 10.1177/0092055x10370120

Price, E. G., Gozu, A., Kern, D. E., Powe, N. R., Wand, G. S., Golden, S., \& Cooper, L. A. (2005). The role of cultural diversity climate in recruitment, promotion and retention of faculty in academic medicine. Journal of General Internal Medicine, 20, 565-571. doi: 10.1111/j.1525-1497.2005.0127.x

Ross, T., Kena, G., Rathbun, A., KewalRamani, A., Zhang, J.,Kristapovich, P., \& Manning, E. (2012). Higher education: Gaps in access and persistence study. National Center for Education Statistics. Alexandria, Virginia.

Shen-Miller, D. S., Forrest, L., \& Burt, M. (2012). Contextual influences on faculty diversity conceptualizations when working with trainee competence problems. The Counseling Psychologist, 40(8), 1181-1219. doi: 10.1177/0011000011431832

Shepard, J. (2011, May 27). 14,000 British professors-but only 50 are black: Higher Education Statistics Agency reveals number of black professors in UK universities has barely changed in eight years. The Guardian. Retrieved from http://www.guardian. co.uk/education/2011/may/27/only-50-black-british-professors 
Sims, C. (2006, February). Broadening the scope of diversity: Implications for recruitment and retention of diverse faculty. Paper presented at the Academy of Human Resource Development International Conference, Columbus OH.

Slaughter, J. B. (2004). Diversity and equity in higher education: A new paradigm for institutional excellence. Johns Hopkins University. Diversity Leadership Council Conference.

Smith, D. G. (2011). Diversity's promise for higher education: Making it work. Baltimore, MD: Johns Hopkins University Press.

Smith, D. G., Turner, C., Osei-Kofi, N., \& Richards, S. (2004). Interrupting the usual: Successful strategies for hiring diverse faculty. The Journal of Higher Education, 75(2), 133-160. doi: 10.1353/jhe.2004.0006

Smith, J. W., \& Casalanti, T. (2005). The influences of gender, race and ethnicity on workplace experiences of institutional and social isolation: An exploratory study of university faculty. Sociological Spectrum, 25(3), 307-334. doi: 10.1080/027321790518735

Snyder, T. D., \& Dillow, S. A. (2012). Digest of education statistics 2011 (NCES 2011-001). National Center for Education Statistics, U.S. Department of Education. Washington, DC. Retrieved from http://nces.ed.gov/pubsearch.

Stanley, C. A. (2007). When counter narratives meet master narratives in the journal editorialreview process. Educational Researcher, 36(1), 14-24. doi: 10.3102/0013189X06298008

Teixeira, R., Halpin, J., Barreto, M., \& Pantoja, A. (2013). Building an all-in nation: A view from the American public. Report by the Center for American Progress.

Turner, C. S. V., Gonzalez, J. C., \& Wood. (2008). Faculty of color in academe: What 20 years of literature tells us. Journal of Diversity in Higher Education, 1(3), 139-168. doi: 10.1037/a0012837

Umbach, P. D. (2006). The contribution of faculty of color to undergraduate education. Research in Higher Education, 47(3), 317-345. doi: 10.1007/s11162-005-9391-3

Vidal-Ortiz, S. (2008). People of color. In R. T. Schaefer (Ed.), Encyclopedia of race, ethnicity, and society (pp. 1037-1039). Thousand Oaks, CA: Sage Publications. doi: http://dx.doi. org/10.4135/9781412963879.

Waller, S. N., Costen, W. M., \& Wozencraft, A. J. (2011). If we admit them, will they stay? Understanding the role of social connectedness in the retention of African American students in a recreation and leisure studies program. Schole: Journal of Leisure Studies and Recreation Education, 26, 30-48. 
Reproduced with permission of the copyright owner. Further reproduction prohibited without permission. 